\title{
ALGUNAS REFLEXIONES EN TORNO A LA CIUDADANÍA ECOLÓGICA Y SU LEGISLACIÓN EN MÉXICO
}

\section{SOME REFLECTIONS ON ECOLOGICAL CITIZENSHIP AND ITS LEGISLATION IN MEXICO}

Jesús Hurtado ${ }^{1}$

\section{RESUMEN}

La investigación aborda el tema de la Ciudadanía Ecológica en México, centrándose en el rol del Estado y su contribución a través de los ordenamientos legales, a la resolución de la problemática medioambiental. Se planteó como objetivo general: determinar si en la normatividad legal vigente en México, se incluyen soluciones para atenuar el accionar humano sobre el medio ambiente, considerando la perspectiva de la ciudadanía ecológica. Para ello, se empleó una aproximación metodológica teórica, vinculando a la ciudadanía ecológica con su trascendencia en el Derecho. Luego, se analizaron las leyes federales, ubicando su objeto, sanciones y las disposiciones tendientes a motivar la corresponsabilidad de los ciudadanos con la práctica de valores en favor de la conservación medioambiental. Los resultados apuntan a que es necesario incorporar en los ordenamientos legales, incentivos que alienten acciones para la conservación de la naturaleza y desmotiven su depredación.

Palabras clave: Ciudadanía, ecología, legislación, educación, protección medioambiental.

\begin{abstract}
The research addresses the issue of Ecological Citizenship in Mexico, focusing on the role of the State and its contribution through legal regulations, to the resolution of environmental problems. It was proposed as a general objective: to determine whether in the legal regulations in force in Mexico, solutions are included to mitigate human actions on the environment, considering the perspective of ecological citizenship. For this, a theoretical methodological approach was used, linking ecological citizenship with its transcendence in Law. Then, the federal laws were analyzed, locating their object, sanctions and the dispositions tending to motivate the co-responsibility of the citizens with the practice of values in favor of environmental conservation. The results point to the need to incorporate incentives in the legal systems that encourage actions for the conservation of nature and discourage its depredation.
\end{abstract}

\footnotetext{
${ }^{1}$ Docente de la Facultad de Contaduría y Administración (FCA) en la Universidad Autónoma de Querétaro, impartiendo las materias relacionadas con contabilidad, Auditoria, Fiscal y Costos, en sus distintos programas de Licenciatura y Maestría, actualmente coordinador de la Maestría en Ciencias económico Administrativas. Universidad Autónoma de Querétaro - México. ORCID: https://orcid.org/0000-0002-4690-9100 E-mail: jesus.hurtadom@uaq.mx
} 
Key words: Citizenship, ecology, legislation, education, environmental protection.

\section{INTRODUCCIÓN}

La ciudadanía ecológica, es el marco para discutir sobre un problema que se encuentra latente en el contexto mundial y en las realidades locales, donde el deterioro del medio ambiente y su correlación con la actividad de los ciudadanos y las actividades económicas, así como el consumismo rampante que no atiende el tratamiento de los residuos y los daños ambientales, es un tema que requiere de soluciones inmediatas, donde el Estado debe ser impulsor de políticas y normas jurídicas que detengan el detrimento originado por la acción humana.

En este artículo, la ciudadanía deja de observarse únicamente como los deberes y derechos contenidos en las normas jurídicas de un contexto geográfico dado, sino que incluye la pertenencia y corresponsabilidad de los ciudadanos, que se manifiestan a través de la práctica de valores (González, 2003), entonces, se hace lo correcto porque esa es la forma de convivir y no como resultado de que se hayan proporcionado incentivos (Dobson, 2005).

De manera que, con un acercamiento teórico que toma como punto de partida la problemática medioambiental, de la ciudadanía y el rol del Estado, particularmente sobre la legislación, se bosquejó como objetivo general: determinar si en la normatividad legal vigente en México, permean soluciones para atenuar el accionar humano sobre el medio ambiente, considerando la perspectiva de la ciudadanía ecológica.

\section{APROXIMACIÓN TEÓRICA A LA CIUDADANÍA ECOLÓGICA}

En el siguiente apartado se estudian los aportes teóricos en torno a la ciudadanía ecológica, el dilema de la sustentabilidad y el rol del Estado. De manera que, se inicia aclarando que existen otros significados que giran alrededor del problema ecológico. Además de la propuesta por Dobson (2005) sobre la Ciudadanía ecológica, se señala la existencia de otra perspectiva denominada ciudadanía ambiental. Dean (2001) propone la expresión ecología verde, mientras que Novo y Murga (2010) presentan la ciudadanía planetaria, que dicen deriva de la propuesta de Dobson, así como del autor Cortina, quien presenta el término de la ciudadanía cosmopolita, con la finalidad de plantear soluciones que atiendan las consecuencias del accionar humano sobre la ecología. 
Para los fines del estudio se adopta la perspectiva de la ciudadanía ecológica, que postula el cuidado medioambiental como efecto de la conciencia del individuo motivado por hacer lo correcto y no como consecuencia de premios o castigos.

\subsection{La ciudadanía ecológica y el rol del Estado.}

Según Dean (2001), la ciudadanía es un concepto antiguo que puede encontrarse en la época de la ciudad-estado ateniense (siglo VII), inclusive antes. Los conceptos modernos de ciudadanía, surgen en el siglo XVII, con rasgos predominantes de la sociedad civil y la administración pública.

En este orden de ideas, Marshall, Casado y Noya (1997) asignan tres periodos de formación de la ciudadanía, el primero se remonta al siglo XVIII donde inicia con los derechos civiles, luego en el siglo XIX la sociedad capitalista trataba los derechos políticos como un derivado de los derechos civiles y para el siglo XX se abandona tal posición, para vincular a la ciudadanía como derechos políticos con una dimensión social. Con esta última posición, la ciudadanía se concibe como "un status que se otorga a los que son miembros de pleno derecho de una comunidad. Todos los que poseen ese status son iguales en lo que se refiere a los derechos y deberes que implica" (p. 312).

Para una mejor comprensión, puede verse en el Diccionario de la Real Academia Española (DRAE, 2018), la definición de ciudadanía, que es entendida como: “cualidad y derecho del ciudadano”. Mientras que para Sojo (2002), la ciudadanía está relacionada con un tema más amplio, que es la forma democrática de gobierno, por lo que las sociedades se involucran en un debate en torno a las características de la relación que surge entre los individuos y el poder, así como del interés particular y las necesidades colectivas. La ciudadanía también puede explicarse desde una perspectiva del deber ser, es decir, los deberes y derechos que están contenidos en las Constituciones y que son atribuibles a las personas que viven en una nación.

De manera que, la ciudadanía se ha extendido hacia las preocupaciones ambientales, consecuentemente se tiene un mayor nivel de conciencia global asociado con el pensamiento ecológico y las responsabilidades que se enlazan con la ciudadanía (Dean, 2001). Entonces, la expresión ecología, se comprende como la "Ciencia que estudia los seres vivos como habitantes de un medio, y las relaciones que mantienen entre si y el propio medio". Para Dobson (2005), 
el aspecto ecológico tiene su área de influencia en la obligación ciudadana que se expresa mediante la noción de la 'huella ecológica' de Wackernagel \& Rees (1998).

En el espacio ecológico, el ciudadano hace lo que debe porque es lo correcto y no como respuesta a incentivos, bajo esta concepción, la ciudadanía ecológica coadyuva a tener una sociedad más sostenible (Dobson, 2005).

La ciudadanía ambiental atiende la cuestión de los derechos ambientales, por lo que su ámbito de actuación es la esfera pública; sus principales atributos son las virtudes liberales de la razonabilidad y la voluntad de aceptar los argumentos más convincentes, así como la legitimidad de los procedimientos; y su referente se limita a las configuraciones políticas modeladas por el Estado-nación (Dobson, 2005).

Por tanto, la ciudadanía ecológica debe contemplarse además "como una herramienta práctica que puede ayudar a conseguir el objetivo social ampliamente aceptado de la sostenibilidad ambiental" (Dobson, 2005, p. 60). Entonces, para González (2003) el perfil de ciudadano que tiene las condiciones para participar en la vida social, considera como características, que debe hacerse responsable de sus actos, es solidario con su grupo social, manifiesta actitudes de honestidad personal y para con los demás, es equitativo y justo. Por lo que hace falta contemplar a la educación para la ciudadanía ambiental como un proceso centrado en valores, que sea vigente en cualquier espacio de la vida pública o privada.

González (2003, p. 613) dice que, la ciudadanía ecológica incluye valores de: responsabilidad, compromiso, solidaridad, equidad, honestidad, con actitudes de identificación, pertenencia y con competencias para la participación.

En consecuencia, el Estado es fundamental para establecer las políticas que tendrán influencia sobre los ciudadanos y sus organizaciones (Aguilar, 1992). Tales políticas deben ser creadas considerando la diferencia entre el problema y la solución, por lo que el Estado es el instrumento para llevar a cabo las políticas públicas, que deben incluir la decisión de solucionar una cuestión que atañe a las colectividades. Las políticas públicas tienen un objetivo definido y surgen cuando el Estado decide ejecutar estrategias en favor de los ciudadanos o un grupo de ellos, son desarrolladas por el sector público, por la comunidad y el sector privado (Lahera, 2004).

Pero además, el Estado es responsable de regular la vida social de los ciudadanos, en cuanto a que debe establecer normas jurídicas -como las leyes-, que contemplen al mismo tiempo, derechos como obligaciones, además de las sanciones cuando no se cumplan las reglas 
o se afecte el derecho de terceros, pero según González (2003) esto no es suficiente, ya que se requiere de una educación que incluya sendos valores, para el accionar ciudadano en favor de la ecología. Asimismo, Novelli (2007) menciona que el Estado por medio del Poder Legislativo determina el sistema legal que valida su actuación. Por lo que, Dobson (2001) se cuestiona si ¿puede articularse una política ecológica en términos de ciudadanía?, contestando que esto es factible.

\subsection{Las evidencias sobre los impactos ambientales}

Foladori (1999) expresa que, la noción de desarrollo sustentable se difunde con el Informe o Comisión Brundtland - Nuestro Futuro Común—, de donde surge su definición, como sigue: "aquel que responde a las necesidades del presente de forma igualitaria pero sin comprometer las posibilidades de sobrevivencia y prosperidad de las generaciones futuras" ( $\mathrm{p}$. 19).

No obstante lo mencionado, los esfuerzos por evidenciar tal situación, surgen en la última parte del siglo XX, a través de diversas iniciativas que enseguida se enuncian (Doménech Quesada, 2007):

- 1972 Club de Roma. Un grupo de científicos empezaron a llamar la atención de los líderes nacionales, para hacerlos conscientes del calentamiento de la Tierra.

- 1979 se celebra en Ginebra la Primera Conferencia Mundial sobre el Clima.

- 1987 surge la Comisión Brundtland.

- 1992 en Río de Janeiro con la Conferencia de la Naciones Unidas sobre el Medio Ambiente y Desarrollo, se adoptó el Convenio Marco sobre el Cambio Climático, con la finalidad de disminuir los gases con efecto invernadero en el año 2000.

- 1997 Conferencia de Kioto. Se refresca el compromiso, determinando como fecha 2012, pero los países en desarrollo no tomaron ninguna responsabilidad.

- 2019. A las diferentes reuniones de líderes mundiales, se ha sumado la convocatoria para el 20 de septiembre, para efectuar la que se denominará Cumbre sobre Cambio Climático 2019, el enfoque de la misma será el plantear soluciones en torno a la industria pesada, la ecología, ciudades, energía, resiliencia y finanzas para el cambio climático (ONU, 2019).

Para explicar el fenómeno medioambiental, Stiglitz (2006) recurre a algunos argumentos de la denominada 'Tragedia de los Comunes' para ilustrar lo que ocurre cuando 
existe un recurso que todos pueden usar libremente; ya que cada uno de los beneficiados no reflexiona en cómo sus acciones pueden perjudicar a los otros, al contrario, todos los usuarios pierden de vista el bien común, por lo que hace un individuo o una nación, lo cual puede perjudicar a otros y no tienen que pagar nada - esto significa que existe una externalidad negativa-, que afecta a todos, no solo a los que emplean los recursos, de manera que los que generan problemáticas ambientales tienden a minimizar el problema.

En este sentido, Daly (2008) dice que, en una sociedad sostenible se espera que los recursos no se utilicen a un ritmo superior al de su regeneración, no se deben emitir contaminantes a un ritmo mayor al que el sistema natural es capaz de absorber o neutralizar, los recursos no renovables no deben consumirse como hasta ahora, debe contemplarse la posibilidad de que el capital humano creado, pueda reemplazar al capital natural perdido.

Lo mencionado por Daly (2008) sería lo ideal, pero según Stiglitz (2006) no es de extrañar que el país más contaminante del mundo sea Estados Unidos, quien arroja a la atmósfera más de seis mil millones de toneladas de dióxido de carbono al año y finja no creer que hay evidencias de que existe la necesidad de limitar las emisiones de gases de efecto invernadero.

Por tanto, Stiglitz (2006) plantea que se debe presionar a los países contaminantes a que dejen de hacerlo y que se establezcan sanciones en caso de que hagan caso omiso a la situación, por lo que los países subdesarrollados deben formar parte de este eje de presión hacia los países desarrollados. Es por ello que, desde diversos frentes se han propuesto estrategias y acciones para paliar el problema. Entre ellos se propone que:

- Deben aplicarse sanciones o impuestos por la importación de productos que se fabrican con procesos productivos contaminantes o dañinos.

- Deben crearse incentivos fiscales para las empresas que empleen métodos responsables con el medio ambiente y los recursos naturales.

- Debe promoverse una regulación global, que tenga mayor jerarquía que las autoridades locales y así evitar que sean objeto de corrupción.

Además, se propone que debe rescatarse una nueva perspectiva cultural, donde se comprenda que todos los individuos somos dañados por un comportamiento que se despliega desde lo local hasta lo global y que los empresarios y la sociedad civil en su conjunto somos responsables por tales daños. Por tanto, desde hace tiempo los interesados en las cuestiones ecológicas, se han preguntado cómo medir los impactos ecológicos, por lo que han surgido 
propuestas como la huella ecológica (Wackernagel \& Rees, 1998), que incluye la propuesta de la huella de carbono (Schneider y Samaniego, 2009).

Para visualizar los impactos de nuestro consumo y su efecto en la naturaleza, se ofrece la definición de la huella ecológica, la que es "una medida de la carga impuesta por una población dada, sobre la naturaleza. Representa el área de tierra necesaria para mantener los niveles actuales de absorción de recursos y la descarga de residuos por parte de esa población" (Wackernagel \& Rees, 1998, p. 5).

Con la aplicación de la huella ecológica, Badii (2008) señala que se ha excedido en el uso del área que correspondería a cada persona. De manera que, enuncia tres realidades sobresalientes:

1. Se posee únicamente 2.1 hectáreas del área mundial biológicamente productiva disponible por cada persona.

2. El promedio mundial de la huella ecológica per cápita es de 2.9 hectáreas globales, lo que significa que se ha venido empleando un excedente con el que no se cuenta (Badii, 2008, p. 674).

3. La biosfera necesita casi un año y cuatro meses para renovarse, con relación a lo que los seres humanos consumimos en un año.

Como un trabajo posterior, surge la huella de carbono que ha sido definida como: "la cantidad de emisión de gases relevantes al cambio climático asociada a las actividades de producción o consumo de los seres humanos (...)” (Schneider y Samaniego, 2009, p.7).

De manera que, debe plantearse una nueva forma de ciudadanía que incluya la comprensión del daño y la contribución para solucionarlo. Las diferentes convenciones en donde han surgido iniciativas globales, han derivado en los Principios básicos de Desarrollo Sostenible (Figura 1), que pretenden ser la pauta para que las naciones y las empresas coadyuven con el grave problema que significa el daño medioambiental. 
Figura 1. Acuerdos internacionales y principios.

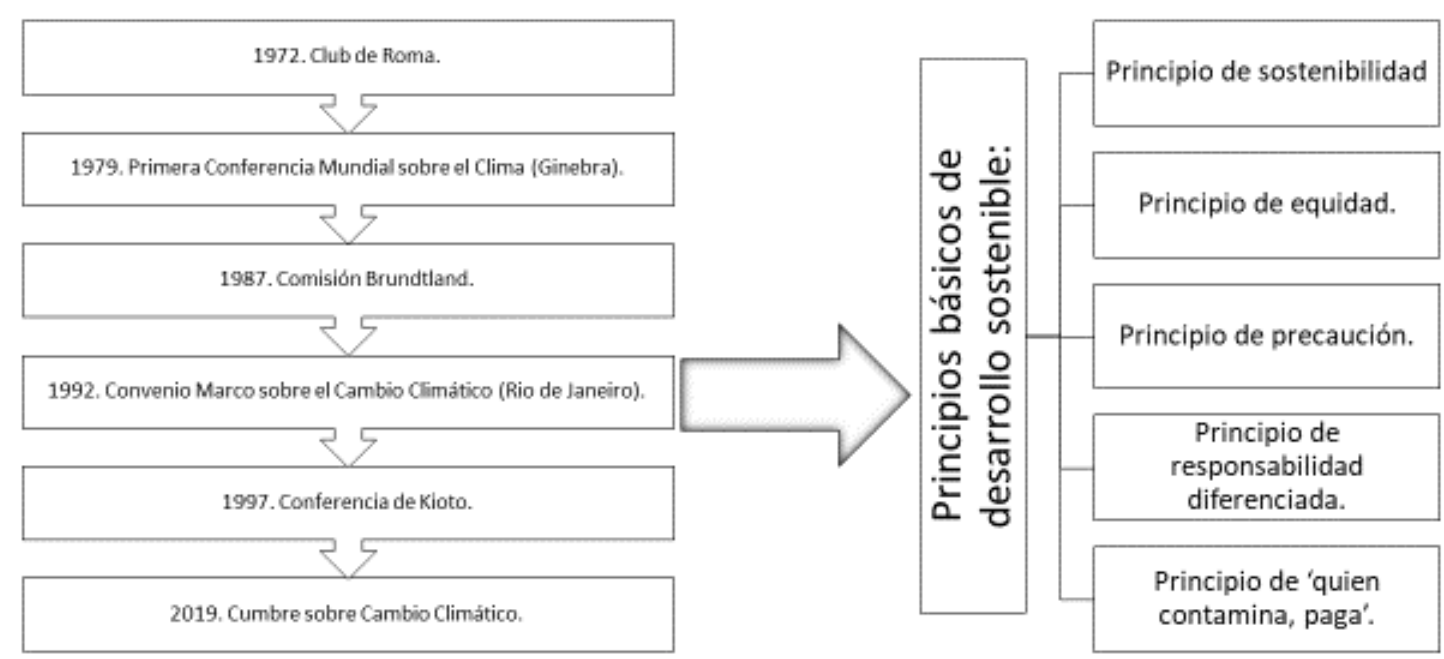

Fuente: Elaborado con base en Doménech Quesada (2007).

En este sentido, se han propuesto los Principios básicos del desarrollo sostenible, que a continuación se explican (Doménech Quesada, 2007, p. 28).

1. Principio de sostenibilidad: Se concibe como el tipo de desarrollo que satisface las necesidades de las generaciones actuales sin poner en peligro las posibilidades de desarrollo de las generaciones futuras.

2. Principio de equidad: Cada individuo tiene derecho, aunque no la obligación, a hacer uso de la misma cantidad de espacio ambiental (energía, materias primas no renovables, terreno agrícola, bosques, capacidad de absorción de $\mathrm{CO} 2$, etc.).

3. Principio de precaución: Es conveniente tomar medidas, antes de tener la seguridad de que se van a producir determinados efectos, debido a la gravedad y alta probabilidad de estos.

4. Principio de responsabilidad diferenciada: Son las obligaciones que un país debe asumir de acuerdo con su responsabilidad en el problema y su grado de desarrollo.

5. Principio de 'quien contamina, paga': Señala que los causantes de perjuicios o de un atentado al medio ambiente deben responder económicamente para su corrección. 
Los principios mencionados, en conjunto con el aporte de la ciudadanía ambiental, contribuyen a sentar las bases para tomar medidas de carácter urgente, para atender las demandas actuales de tipo medioambiental e impulsar normas jurídicas que garanticen la aplicación de los principios antes mencionados.

\section{METODOLOGÍA}

El objetivo propuesto fue: determinar si en la normatividad legal vigente en México, permean soluciones para atenuar el accionar humano sobre el medio ambiente, considerando la perspectiva de la Ciudadanía Ecológica.

A efecto de cumplir con el objetivo planteado, se realizó un acercamiento teórico a las perspectivas que atienden el tema de la Ciudadanía Ecológica, considerando además el estudio de la problemática ambiental y su trascendencia en el Derecho. Se llevó a cabo, una búsqueda acuciosa de las leyes vigentes que atienden dicha temática, así como de los aportes doctrinales de diferentes teóricos en la disciplina. Por tanto, el estudio corresponde a una aproximación metodológica teórica, que implicó la comparación de las normas jurídicas en materia ecológica, a efecto de identificar sus características, alcance y actualidad en la resolución de los problemas que atañen a los ciudadanos.

\section{RESULTADOS Y DISCUSIÓN}

Como se ha presentado en la perspectiva teórica, los diferentes aportes en materia de cuidado ecológico que promueven los organismos internacionales han puesto el tema en el escenario mundial, pero ello no es suficiente si no se atiende el problema con ordenamientos jurídicos que detengan las acciones nocivas para el planeta. Por lo que se reconoce que la ciudadanía ecológica va más allá de los meros planteamientos que surgen de la disciplina del Derecho, que se integra entre sus caracteres a la bilateralidad, exterioridad, coercibilidad, heteronomía e imperatividad (García - Maynez, 2002); los que en su conjunto son los que dan forma a los ordenamientos jurídicos, como la constitución, las leyes, reglamentos, entre otros, que surgen de la necesidad de las personas que viven en sociedad y que sirven como el mecanismo con el que Estado genera y determina para resolver controversias, así como procurar una sana convivencia. 


\subsection{Características de la normatividad}

El artículo $3^{\circ}$ de la Constitución Política de los Estados Unidos Mexicanos, publicada en 1917 y reformada por última vez el 20 de febrero de 2020 (CPEUM, 2020), contempla en el tema de la educación, que los planes y programas de estudio incluirán temáticas de cuidado al medio ambiente. Mientras que el artículo $4^{\circ}$ quinto párrafo, indica que:

"Toda persona tiene derecho a un medio ambiente sano para su desarrollo y bienestar. El Estado garantizará el respeto a este derecho. El daño y deterioro ambiental generará responsabilidad para quien lo provoque en términos de lo dispuesto por la ley." (CPEUM, 2020, p. 10).

Cabe indicar que la Constitución incluye en diversos artículos transitorios, la obligatoriedad del Congreso de la Unión, para reformar las leyes y adecuarlas a los preceptos mencionados.

En consecuencia, es relevante confirmar si el Estado ha tomado una directriz adecuada a través de las leyes vigentes y si estas son instrumentos eficaces para garantizar la solución de los problemas medioambientales. Se parte de que es posible articular una política ecológica considerando a la ciudadanía como eje toral (Dobson, 2001) y que en México las leyes cobran vigencia por la aprobación del Congreso de la Unión, su promulgación y publicación en el órgano oficial del Estado.

De esta manera, los caracteres a que se refiere García - Maynez (2002), se identificarán en las normas mexicanas en materia ambiental (Tabla 1), por lo que hace falta explicar el significado de las características y su especificidad vinculada con las leyes ecológicas en México.

Tabla 1. Características de las normas jurídicas enfocadas al tema ecológico en México.

\begin{tabular}{|c|l|l|}
\hline Característica & \multicolumn{1}{|c|}{ Significado } & $\begin{array}{c}\text { Especificidad en las leyes } \\
\text { ecológicas }\end{array}$ \\
\hline Bilateralidad & $\begin{array}{l}\text { Se refiere a la imposición de } \\
\text { derechos y obligaciones para las } \\
\text { partes que intervienen en el acto. }\end{array}$ & $\begin{array}{l}\text { Personas que participan en el } \\
\text { acto (ciudadano y Estado). }\end{array}$ \\
\hline
\end{tabular}




\begin{tabular}{|c|l|l|}
\hline Coercibilidad & $\begin{array}{l}\text { La inobservancia conlleva } \\
\text { necesariamente a una } \\
\text { consecuencia. }\end{array}$ & $\begin{array}{l}\text { Infracciones y sanciones } \\
\text { económicas y/o penas } \\
\text { corporales. }\end{array}$ \\
\hline Exterioridad & $\begin{array}{l}\text { Busca regular y en su caso } \\
\text { sancionar conductas que se } \\
\text { originan en el plano social. }\end{array}$ & $\begin{array}{l}\text { Conductas y sanciones que } \\
\text { surgen del actuar de las } \\
\text { personas. }\end{array}$ \\
\hline Heteronomía & $\begin{array}{l}\text { Significa que las normas } \\
\text { jurídicas son creadas por otra } \\
\text { persona distinta al destinatario } \\
\text { de la norma. }\end{array}$ & $\begin{array}{l}\text { La norma sigue un proceso, } \\
\text { entonces es emitida por el } \\
\text { Congreso de la Unión. }\end{array}$ \\
\hline Imperatividad & $\begin{array}{l}\text { Implica que las normas son } \\
\text { mandatos y como tales deben ser } \\
\text { cumplidos a la exigencia de otra } \\
\text { persona o ente. }\end{array}$ & $\begin{array}{l}\text { Existen mecanismos para hacer } \\
\text { cumplir la ley. }\end{array}$ \\
\hline
\end{tabular}

Fuente: Elaboración propia con base en García - Maynez (2002).

Atendiendo a las características mencionadas en la tabla previa, se realizó una búsqueda de los dispositivos legales que atienden el asunto ambiental en México, encontrando que existen doce instrumentos que regulan temas de agua, suelo, aire, desarrollo rural, residuos y otros similares. Tales normas enseguida se enlistan:

1. Ley General del Equilibrio Ecológico y Protección al Ambiente, publicada el 28/01/1988 y reformada el 05/06/2017

2. Ley de Aguas Nacionales, publicada el 01/12/1992 y reformada el 24/03/2016

3. Ley General de Desarrollo Forestal Sustentable, publicada el 05/06/2018

4. Ley General de Vida Silvestre, publicada el 03/07/2000 y reformada el $19 / 01 / 2018$

5. Ley de Desarrollo Rural Sustentable, publicada el 07/12/2001 y reformada el $12 / 04 / 2019$ 
6. Ley General para la Prevención y Gestión Integral de Residuos, publicada el 08/10/2003 y reformada el 19/01/2018

7. Ley de Bioseguridad de Organismos Genéticamente Modificados, publicada el $18 / 03 / 2005$

8. Ley de Productos Orgánicos, publicada el 07/02/2006

9. Ley General de Pesca y Acuacultura Sustentables, publicada el 24/07/2007 y reformada el 24/04/2018

10. Ley de Promoción y Desarrollo de los Bioenergéticos, publicada el $01 / 02 / 2008$

11. Ley Federal de Responsabilidad Ambiental, publicada el 07/06/2013, y

12. Ley General de Cambio Climático, publicada el 06/06/2012 y reformada el 13/07/2018.

Considerando la información oficial del Centro de Estudios Sociales y de Opinión Pública (2006), dependiente de la Cámara de Diputados, se estableció que en México se reconoce que el problema medioambiental es tema internacional que atañe a la nación, ya que se encontró que desde 1936, entre convenciones, acuerdos, protocolos, anexos y enmiendas, se han firmado 77 tratados internacionales o acuerdos en materia de medio ambiente, destaca que dieciocho de ellos se suscribieron con Estados Unidos, con enfoque en la protección del medio ambiente, el tratamiento de desechos de residuos tóxicos y peligrosos en la frontera norte. Los tratados internacionales fueron suscritos con países y organismos internacionales como la Organización Marítima Internacional y la Organización de las Naciones Unidas, la UNESCO y la Organización de Estados Americanos.

\subsection{Estudio de las leyes ecológicas.}

En congruencia con lo establecido con Dean (2001) se esperaría que en las leyes se haya retomado el concepto de ciudadanía ecológica, para evidenciar el nivel de conciencia global relacionada con el pensamiento ecológico y las responsabilidades que implican la ciudadanía. Por tanto, se realizó un análisis del contenido de las normas, a efecto de establecer si cuentan con las características necesarias y funcionan como mecanismos que conduzcan a la práctica de la ciudadanía ecológica. En este sentido, para la aplicación de las leyes se requiere que se incluya la bilateralidad, la que está presente cuando en la norma se reconocen los sujetos, por lo que son identificados como el Estado y las personas que se ubican en las hipótesis de ley. En 
cuanto a la heteronomía, se reconoce como el órgano responsable al Congreso de la Unión, que forma parte del Poder Legislativo. En lo que incumbe a la exterioridad, se estableció que en las leyes se mencionan las conductas en que puede ubicarse un ciudadano, confiriéndole derechos y obligaciones en el tema ecológico.

Por lo que, habiendo identificado las leyes en materia ecológica, con la finalidad de determinar el enfoque centrado en la resolución y/o prevención, se buscó identificar a través del objeto, las infracciones y sanciones; ubicar los ordenamientos jurídicos que incluyeran acciones tendientes a promover la ciudadanía ecológica (Tabla 2).

Tabla 2. Legislación ecológica en México.

\begin{tabular}{|c|c|c|}
\hline Ley & Objeto & Infracciones y sanciones \\
\hline $\begin{array}{l}\text { Ley General del } \\
\text { Equilibrio } \\
\text { Ecológico y } \\
\text { Protección al } \\
\text { Ambiente } \\
\text { (2017). }\end{array}$ & $\begin{array}{l}\text { Preservación y restauración del } \\
\text { equilibrio ecológico, así como a la } \\
\text { protección al ambiente, propiciando el } \\
\text { desarrollo sustentable. }\end{array}$ & $\begin{array}{c}\text { Contempla sanciones } \\
\text { administrativas según otras } \\
\text { disposiciones. Además, } \\
\text { establece arresto } \\
\text { administrativo y decomiso de } \\
\text { bienes. }\end{array}$ \\
\hline $\begin{array}{c}\text { Ley de Aguas } \\
\text { Nacionales } \\
\text { (2016). }\end{array}$ & $\begin{array}{l}\text { Regular la explotación, uso o } \\
\text { aprovechamiento de las aguas, su } \\
\text { distribución y control, así como la } \\
\text { preservación de su cantidad y calidad } \\
\text { para lograr su desarrollo integral } \\
\text { sustentable. }\end{array}$ & $\begin{array}{c}\text { Sanciones administrativas, } \\
\text { multas por infracciones } \\
\text { fiscales, arresto } \\
\text { administrativo, decomiso de } \\
\text { bienes, además de la } \\
\text { demolición de construcciones } \\
\text { que originaron la sanción. }\end{array}$ \\
\hline $\begin{array}{l}\text { Ley General de } \\
\text { Desarrollo } \\
\text { Forestal } \\
\text { Sustentable } \\
\text { (2018). }\end{array}$ & $\begin{array}{l}\text { Regular y fomentar el manejo integral } \\
\text { y sustentable de los territorios } \\
\text { forestales, la conservación, protección, } \\
\text { restauración, producción, ordenación, } \\
\text { el cultivo, manejo y aprovechamiento } \\
\text { de los ecosistemas forestales del país y }\end{array}$ & $\begin{array}{l}\text { Infracciones como: } \\
\text { amonestación, imposición de } \\
\text { multa, suspensión de las } \\
\text { autorizaciones de } \\
\text { aprovechamiento de recursos } \\
\text { forestales, revocación de }\end{array}$ \\
\hline
\end{tabular}




\begin{tabular}{|c|c|c|}
\hline & $\begin{array}{l}\text { sus recursos; así como distribuir las } \\
\text { competencias que en materia forestal } \\
\text { correspondan a la Federación, las } \\
\text { Entidades Federativas. }\end{array}$ & $\begin{array}{l}\text { autorización, decomiso de los } \\
\text { productos obtenidos, clausura } \\
\text { de las instalaciones, y } \\
\text { establecimiento de medidas } \\
\text { de restauración de las áreas } \\
\text { afectadas, multas que van de } \\
\text { los } 40 \text { a 30,000 UMAS*. }\end{array}$ \\
\hline $\begin{array}{l}\text { Ley General de } \\
\text { Vida Silvestre } \\
\text { (2018). }\end{array}$ & $\begin{array}{c}\text { Establecer la concurrencia del } \\
\text { Gobierno Federal, de los gobiernos de } \\
\text { los Estados y de los Municipios, en el } \\
\text { ámbito de sus respectivas } \\
\text { competencias, relativa a la } \\
\text { conservación y aprovechamiento } \\
\text { sustentable de la vida silvestre y su } \\
\text { hábitat en el territorio de la República } \\
\text { Mexicana y en las zonas en donde la } \\
\text { Nación ejerce su jurisdicción. }\end{array}$ & $\begin{array}{c}\text { Sanciones administrativas } \\
\text { como: amonestación escrita, } \\
\text { multa, suspensión temporal } \\
\text { parcial o total, revocación de } \\
\text { licencias, clausura, arresto } \\
\text { administrativo, decomiso de } \\
\text { los instrumentos relacionados } \\
\text { con la infracción. Las multas } \\
\text { van de } 20 \text { a } 75,000.00 \\
\text { UMAS. }\end{array}$ \\
\hline $\begin{array}{c}\text { Ley de } \\
\text { Desarrollo } \\
\text { Rural } \\
\text { Sustentable } \\
\text { (2019). }\end{array}$ & $\begin{array}{l}\text { Promover el desarrollo rural } \\
\text { sustentable del país, propiciar un } \\
\text { medio ambiente. }\end{array}$ & $\begin{array}{l}\text { No establece sanciones, ni } \\
\text { multas. }\end{array}$ \\
\hline $\begin{array}{c}\text { Ley General } \\
\text { para la } \\
\text { Prevención y } \\
\text { Gestión Integral } \\
\text { de Residuos } \\
\text { (2018). }\end{array}$ & $\begin{array}{l}\text { Garantizar el derecho de toda persona } \\
\text { al medio ambiente sano y propiciar el } \\
\text { desarrollo sustentable a través de la } \\
\text { prevención de la generación, la } \\
\text { valorización y la gestión integral de } \\
\text { los residuos peligrosos, de los residuos } \\
\text { sólidos urbanos y de manejo especial; } \\
\text { prevenir la contaminación de sitios }\end{array}$ & $\begin{array}{l}\text { Además de la remediación del } \\
\text { daño, sanciones penales y } \\
\text { administrativas } \\
\text { correspondientes por } \\
\text { infracciones, se estará a lo } \\
\text { dispuesto en la Ley General } \\
\text { del Equilibrio Ecológico y la } \\
\text { Protección al Ambiente. }\end{array}$ \\
\hline
\end{tabular}




\begin{tabular}{|c|c|c|}
\hline & $\begin{array}{c}\text { con estos residuos y llevar a cabo su } \\
\text { remediación. }\end{array}$ & \\
\hline $\begin{array}{c}\text { Ley de } \\
\text { Bioseguridad de } \\
\text { Organismos } \\
\text { Genéticamente } \\
\text { Modificados } \\
\text { (2005). }\end{array}$ & $\begin{array}{l}\text { Regular las actividades de utilización } \\
\text { confinada, liberación experimental, } \\
\text { liberación en programa piloto, } \\
\text { liberación comercial, } \\
\text { comercialización, importación y } \\
\text { exportación de organismos } \\
\text { genéticamente modificados, con el fin } \\
\text { de prevenir, evitar o reducir los } \\
\text { posibles riesgos que estas actividades } \\
\text { pudieran ocasionar a la salud humana } \\
\text { o al medio ambiente y a la diversidad } \\
\text { biológica o a la sanidad animal, } \\
\text { vegetal y acuícola. }\end{array}$ & $\begin{array}{c}\text { Establece sanciones } \\
\text { administrativas en caso de } \\
\text { incumplimiento de las } \\
\text { personas que infrinjan los } \\
\text { preceptos de la Ley, sus } \\
\text { reglamentos y las normas } \\
\text { oficiales mexicanas que de } \\
\text { ella deriven. }\end{array}$ \\
\hline $\begin{array}{l}\text { Ley de } \\
\text { Productos } \\
\text { Orgánicos } \\
\text { (2006). }\end{array}$ & $\begin{array}{l}\text { Promover y regular los criterios y/o } \\
\text { requisitos para la conversión, } \\
\text { producción, procesamiento, } \\
\text { elaboración, preparación, } \\
\text { acondicionamiento, almacenamiento, } \\
\text { identificación, empaque, etiquetado, } \\
\text { distribución, transporte, } \\
\text { comercialización, verificación y } \\
\text { certificación de productos producidos } \\
\text { orgánicamente. }\end{array}$ & $\begin{array}{l}\text { Establece sanciones previstas } \\
\text { en otros ordenamientos, la } \\
\text { secretaria multará de } 5,000 \text { a } \\
\text { 45,000 veces el salario } \\
\text { mínimo }\end{array}$ \\
\hline $\begin{array}{l}\text { Ley General de } \\
\text { Pesca y } \\
\text { Acuacultura } \\
\text { Sustentables } \\
\text { (2018). }\end{array}$ & $\begin{array}{l}\text { Regular, fomentar y administrar el } \\
\text { aprovechamiento de los recursos } \\
\text { pesqueros y acuícolas en el territorio } \\
\text { nacional y las zonas sobre las que la }\end{array}$ & $\begin{array}{c}\text { Establece sanciones de } \\
\text { carácter penal o civil. Las } \\
\text { multas serán de } 10 \text { a } 30,000 \\
\text { salarios mínimos. }\end{array}$ \\
\hline
\end{tabular}




\begin{tabular}{|c|c|c|}
\hline & $\begin{array}{c}\text { nación ejerce su soberanía y } \\
\text { jurisdicción. }\end{array}$ & \\
\hline $\begin{array}{c}\text { Ley de } \\
\text { Promoción y } \\
\text { Desarrollo de } \\
\text { los } \\
\text { Bioenergéticos } \\
\text { (2008). }\end{array}$ & $\begin{array}{l}\text { La promoción y desarrollo de los } \\
\text { Bioenergéticas con el fin de coadyuvar } \\
\text { a la diversificación energética y el } \\
\text { desarrollo sustentable como } \\
\text { condiciones que permiten garantizar el } \\
\text { apoyo al campo mexicano. }\end{array}$ & $\begin{array}{c}\text { Se impondrán sanciones por } \\
\text { infracciones, de } 1,000 \text { a } \\
\text { 100,000 veces de salario } \\
\text { mínimo, según la Ley Federal } \\
\text { de Responsabilidad } \\
\text { Administrativa de los } \\
\text { Servidores Públicos. }\end{array}$ \\
\hline $\begin{array}{l}\text { Ley Federal de } \\
\text { Responsabilidad } \\
\text { Ambiental } \\
\text { (2013). }\end{array}$ & $\begin{array}{l}\text { La protección, la preservación y } \\
\text { restauración del ambiente y el } \\
\text { equilibrio ecológico, para garantizar } \\
\text { los derechos humanos a un medio } \\
\text { ambiente sano para el desarrollo y } \\
\text { bienestar de toda persona, y a la } \\
\text { responsabilidad generada por el daño y } \\
\text { el deterioro ambiental. }\end{array}$ & $\begin{array}{l}\text { Se establecen sanciones de } \\
\text { conformidad con la Ley } \\
\text { General del Equilibrio } \\
\text { Ecológico y la Protección al } \\
\text { Ambiente. }\end{array}$ \\
\hline $\begin{array}{l}\text { Ley General de } \\
\text { Cambio } \\
\text { Climático } \\
\text { (2018). }\end{array}$ & $\begin{array}{l}\text { Garantizar el derecho al medio } \\
\text { ambiente sano, regular la emisión de } \\
\text { gases y compuestos de efecto } \\
\text { invernadero, regular las acciones de } \\
\text { mitigación y adaptación del cambio } \\
\text { climático. } \\
\text { Reducir la vulnerabilidad de la } \\
\text { población y los ecosistemas del país } \\
\text { frente a los efectos adversos del } \\
\text { cambio climático. } \\
\text { Fomentar la educación, investigación, } \\
\text { desarrollo y transferencia de }\end{array}$ & $\begin{array}{l}\text { Sanciones administrativas } \\
\text { según la Ley Federal de } \\
\text { Responsabilidades } \\
\text { Administrativas de los } \\
\text { Servidores Públicos y otras } \\
\text { aplicables, sin perjuicio de la } \\
\text { responsabilidad civil y penal. } \\
\text { Se podrán ordenar las } \\
\text { medidas de seguridad de la } \\
\text { Ley General del Equilibrio } \\
\text { Ecológico y Protección al } \\
\text { Ambiente. }\end{array}$ \\
\hline
\end{tabular}




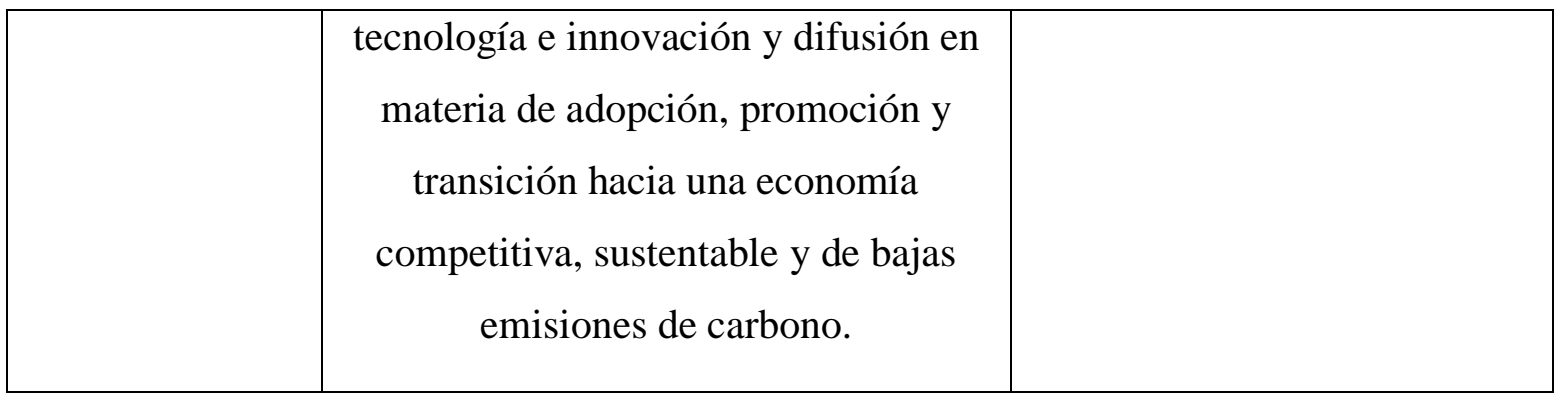

Fuente: Elaboración propia con apoyo en las leyes citadas.

*UMA = Unidad de medida actualizada.

De manera que del análisis de los ordenamientos jurídicos se desprende que:

1. En México los ordenamientos legales de orden federal, son formulados y reformados por el Congreso de la Unión, su publicación queda a cargo del Presidente de la República. Por su parte, los ordenamientos de carácter local son creados por las Legislaturas de las Entidades Federativas y se dan a conocer en los periódicos oficiales. 2. La Constitución incluye como mandato, la obligatoriedad de proveer a los ciudadanos un medio ambiente sano, por lo que se instruye a establecer las normas que coadyuven al logro del mismo.

3. Casi en su totalidad (con excepción de la Ley de Desarrollo Rural Sustentable, 2019) se establecen infracciones y sanciones. Las sanciones son multas, que se expresan en dinero.

4. Algunas legislaciones establecen sanciones administrativas, que remiten a la Ley General del Equilibrio Ecológico y la Protección al Ambiente.

5. La Ley Federal de Responsabilidad Ambiental (2013), considera la protección, el cuidado, la reparación del ambiente y el equilibrio ecológico, como un derecho humano.

6. La gestión de los desechos está contemplada en la Ley General para la Prevención y Gestión Integral de Residuos (2018), considerando que debe garantizarse el derecho de las personas a un medio ambiente sano.

7. Solo la Ley General de Cambio Climático (2018), incluye en su objeto, el tema de la educación para garantizar el derecho a un medio ambiente sano. Asimismo, reconoce la obligatoriedad de la Federación, las Entidades federativas y los municipios, para promover la educación sobre el tema. 
8. Además, la Ley General de Cambio Climático (2018), establece la creación del Instituto Nacional de Ecología y Cambio Climático, como organismo responsable de las acciones tendientes a la educación sobre asuntos de cambio climático, asimismo, se establece la creación de un fondo para su financiamiento.

Como se desprende del último punto, la Ley General de Cambio Climático (2018) fue publicada el 6 de junio de 2012 y reformada el 13 de julio de 2018 evidenciando la preocupación del Poder legislativo para reconocer el tema de la educación ambiental, como importante y necesaria para la sociedad.

De manera que, las disposiciones contenidas en la Ley General de Cambio Climático (2018) y que prevén la educación en el tema, se encuentran contenidas en los artículos 7, 8 y 10, estableciendo que la federación es responsable de:

"XI. Promover la educación y difusión de la cultura en materia de cambio climático en todos los niveles educativos, así como realizar campañas de educación e información para sensibilizar a la población sobre las causas y los efectos de la variación del clima;" (Artículo 7-XI).

Es tal disposición muy importante, ya que al introducir la educación ambiental en todos los niveles de educación, se garantiza que la formación de los niños y jóvenes estaría apoyada en este tema y con ello cambiar actitudes y costumbres contrarias a la conservación de la naturaleza. Por lo que ahora resulta interesante, analizar cómo la Secretaría de Educación, instrumenta este mandato legal.

Asimismo, se le atribuye a las entidades federativas y a los municipios, realizar campañas sobre los efectos adversos del cambio climático (artículo 8-X y 9-V, de la Ley General de Cambio Climático, 2018).

Aunado a lo mencionado, en la Ley General de Cambio Climático (2018), se establece la creación del Instituto Nacional de Ecología y Cambio Climático (INECC), el que tendrá diversas responsabilidades, entre ellas:

"Artículo 22. El INECC tendrá las atribuciones siguientes:

XII. Proponer al Sistema Educativo Nacional el contenido educativo de libros, libros de texto y materiales didácticos sobre cambio climático, de conformidad con la Ley General de Educación;

XIII. Fomentar, en coordinación con la Secretaría de Educación Pública y las instituciones de investigación y educación superior del país, la capacidad científica, tecnológica y de innovación, en materia de desarrollo sustentable, medio ambiente y cambio climático;

XXII. Participar en iniciativas, comités y consorcios ambientales científicos y de investigación, educación y capacitación, tanto nacionales como internacionales;" (Ley General de Cambio Climático, 2018). 
Además, la legislación (Ley General de Cambio Climático, 2018) contiene disposiciones tendientes a la reducción de emisiones, cuyos responsables serán la Federación, Estados y municipios, así como se instruye a incluir a las empresas y sus trabajadores (artículo 34-VI, Ley General de Cambio Climático, 2018).

Finalmente, debe decirse que la ciudadanía ecológica requiere de la práctica de valores, para que se haga lo que es adecuado, por lo que esta perspectiva no se encuentra disociada del Derecho, pues se está viviendo una realidad que ya no es nueva, que implica reconocer la problemática por el accionar humano y que se traduce en un problema medioambiental grave, entonces las normas se presentan como una forma de control y coerción social para organizar y reorganizar la forma en cómo se hacen las cosas y así vivir en armonía. El aporte que se hace en materia legislativa, por medio de la Ley General de Cambio Climático (2018), es importante y de gran trascendencia. No obstante, se requiere que dicha legislación se exprese en acciones tangibles y que el INECC se convierta en un organismo influyente en la política educativa, de salud y principalmente aporte a las políticas públicas que habrán de construirse.

\section{CONCLUSIONES}

Los resultados muestran que en México existe una importante colección de leyes que regulan el tema ecológico, pero que dichos ordenamientos jurídicos en su mayoría incluyen infracciones y sanciones por el daño a la ecología. Asimismo, dichas leyes no motivan la educación en materia ecológica, únicamente en la Ley General de Cambio Climático (2018) se pudo observar la introducción del lenguaje propio de organismos no gubernamentales que procuran el cuidado medioambiental. Asimismo, se advirtió que en dicha Ley se prevé el fomento de la educación, la investigación, desarrollo y transferencia de tecnología e innovación y difusión en materia de adopción, promoción y transición a una economía competitiva, sustentable y con bajas emisiones de carbono

Desde la perspectiva de Dobson (2005), el ser humano en su convivencia social, identifica la relevancia del espacio ecológico, por lo que al ser un buen ciudadano hace lo que debe porque es lo correcto, lo que implica un acto voluntario y coherente en su rol de convivencia en el entorno social y no como respuesta a incentivos. No obstante, las evidencias perceptibles sobre el daño ecológico, hace necesaria la incorporación de incentivos que motiven acciones tendientes a conservar el entorno ecológico y desmotiven acciones de depredación de 
la naturaleza. Todo ello, nos conduce a la imperiosa necesidad de institucionalizar la ciudadanía ecológica como un requisito indispensable de sana convivencia. De manera que, en México debe proponerse la introducción de normas jurídicas que no solo sancionen las conductas inadecuadas, sino que motiven una cultura de prevención e introduzcan temas educativos desde la formación temprana.

El esfuerzo del Estado mexicano para promover e impulsar leyes que tengan por objeto la para garantizar los derechos humanos a un medio ambiente sano y el bienestar de la persona, no han detenido el daño ecológico, por lo que deben impulsarse políticas públicas

Por lo mencionado, el Estado mexicano debe ser impulsor de políticas públicas y ordenamientos jurídicos que impulsen la preservación y restauración del equilibrio ecológico, y que al mismo tiempo detengan el deterioro originado por el accionar humano. Es por ello que, deben reformarse las leyes existentes, garantizando su cumplimiento y generando acciones que se traduzcan en resultados tangibles.

\section{REFERENCIAS BIBLIOGRÁFICAS:}

AGUILAR, Villanueva Luis F. El Estudio de las Políticas Públicas. 3a. Ed., 1992, México: Miguel Ángel Porrúa.

BADII, Mohammad. H. "La huella ecológica y sustentabilidad". Daena: International Journal of Good Conscience, 2008, 3(1), pp. 672-678. Marzo 2008. ISSN 1870-557X.

CENTRO DE ESTUDIOS SOCIALES Y DE OPINIÓN PÚBLICA. "Contexto internacional en Medio ambiente", 2006, [Actualización: 28 de agosto de 2006]. Desde http://archivos.diputados.gob.mx/Centros_Estudio/Cesop/Eje_tematico/9_mambiente.htm\#[Ci $\operatorname{tar} \% 20 \mathrm{como}]$

DALY, Mary. "Parenting in contemporary Europe: A positive Approach”. Strasbourg: Council of Europe Publications, 2008, 1-15.

DEAN, Hartley. "Green Citizenship", Social Policy \& Administration”. ISSN 0144 - 5596. Vol. 35, No. 5, December 2001, pp. 490 - 505. Desde https://onlinelibrary.wiley.com/doi/abs/10.1111/1467-9515.t01-1-00249

DOBSON, Andrew. “Ciudadanía Ecológica”. Isegoría. No. 24, 2001, pp. 167-187. Desde https://doi.org/10.3989/isegoria.2001.i24.610

DOBSON, Andrew. “Ciudadanía Ecológica ¿una influencia desestabilizadora?”. Isegoría. No. 32, 2005, pp. 47-62. Desde http://isegoria.revistas.csic.es/index.php/isegoria/article/view/437/438 
DOMÉNECH Quesada, J.L. “huella ecológica y desarrollo sostenible”. Madrid: AENOR. 2007.

DRAE. Ciudadanía y Ecología. Diccionario de la Real Academia Española. 2018, Desde https://www.rae.es/

FOLADORI, Guillermo. "Sustentabilidad ambiental y contradicciones sociales". Ambiente e Sociedade, 1999, Campinas, a.2., n.5. pp. 19-34.

GARCÍA - MÁYNEZ, Eduardo. Introducción al estudio del Derecho. 53ª ed. 2002, México: Porrúa.

GONZÁLEZ, Gaudiano Edgar. "Educación para la ciudadanía ambiental”. Interciencia, Asociación Interciencia Caracas, 2003, Venezuela vol. 28, núm. 10, octubre, 2003, pp. 611 615.

LAHERA, Eugenio P. "Política y políticas públicas". División de desarrollo social, 2004, Santiago de Chile: CEPAL.

MARSHALL, Thomas Humpehrey. CASADO, Teresa. y NOYA Francisco Javier Miranda, "Ciudadanía y clase social”. Reis: Revista Española de Investigaciones Sociológicas. No. 79 (Jul. - Sep., 1997), pp. 297-344

NOVELLI, Mariano Horacio. "Los Principios Generales de da Tributación en la Constitución Argentina”. Crónica Tributaria., 2007, Núm. 122, págs. 121-135.

NOVO, María. y MURGA, M. Ángeles. "Educación ambiental y ciudadanía planetaria". Revista Eureka sobre Enseñanza y Divulgación de las Ciencias, vol. 7, 2010, pp. 179-186 Asociación de Profesores Amigos de la Ciencia, EUREKA Cádiz, España. Desde https://www.redalyc.org/pdf/920/92013009003.pdf

ONU. "Cambio climático". Organización de las Naciones Unidas, 2019, Desde http://www.un.org/es/sections/issues-depth/climate-change/index.html

SCHNEIDER. Heloísa, y SAMANIEGO, Joseluis. "La huella del carbono en la producción, distribución y consumo de bienes y servicios". Chile: CEPAL. 2009, Desde https://repositorio.cepal.org/bitstream/handle/11362/3753/S2009834_es.pdf?sequence=1\&isA llowed $=\mathrm{y}$

SOJO, Carlos. "La noción de ciudadanía en el debate latinoamericano". Revista de la CEPAL 76, 2002, pp. 25 -78. Desde

https://repositorio.cepal.org/bitstream/handle/11362/10799/076025038_es.pdf?sequence=1\&i sAllowed $=\mathrm{y}$

STIGLITZ, Joseph Eugene. “Cómo hacer que funcione la globalización”. México: Taurus. 2006. 
WACKERNAGEL, Mathis. \& REES, William. “Our Ecological Footprint: Reducing Human Impact on the Earth". Canadian: New Society Publisher, 1998.

\section{Anexo legislativo:}

CPEUM. Constitución Política del Estados Unidos Mexicanos. Diario Oficial de la Federación. 2020. Desde http://www.diputados.gob.mx/LeyesBiblio/ref/cpeum.htm

Ley de Aguas Nacionales. H. Congreso de la Unión, México. Diario Oficial de la Federación. 2016. Desde: http://www.diputados.gob.mx/LeyesBiblio/pdf/16_240316.pdf

Ley de Bioseguridad de Organismos Genéticamente Modificados. H. Congreso de la Unión, México. Diario Oficial de la Federación. 2005. Desde:

http://www.diputados.gob.mx/LeyesBiblio/pdf/LBOGM.pdf

Ley de Bioseguridad de Organismos Genéticamente Modificados. H. Congreso de la Unión, México. Diario Oficial de la Federación. 2005. Desde:

http://www.diputados.gob.mx/LeyesBiblio/pdf/LPO.pdf

Ley de Desarrollo Rural Sustentable. H. Congreso de la Unión, México. Diario Oficial de la Federación. 2019. Desde: http://www.diputados.gob.mx/LeyesBiblio/pdf/235_120419.pdf

Ley de Promoción y Desarrollo de los Bioenergéticos. H. Congreso de la Unión, México. Diario Oficial de la Federación. 2008. Desde: http://www.diputados.gob.mx/LeyesBiblio/pdf/LPDB.pdf

Ley Federal de Responsabilidad Ambiental. H. Congreso de la Unión, México. Diario Oficial de la Federación. 2013. Desde: http://www.diputados.gob.mx/LeyesBiblio/pdf/LFRA.pdf

Ley General de Cambio Climático. H. Congreso de la Unión, México. Diario Oficial de la Federación. 2018. Desde: http://www.diputados.gob.mx/LeyesBiblio/pdf/LGCC_130718.pdf

Ley General de Desarrollo Forestal Sustentable. H. Congreso de la Unión, México. Diario Oficial de la Federación. 2018. Desde:

http://www.diputados.gob.mx/LeyesBiblio/pdf/LGDFS_050618.pdf

Ley General de Pesca y Acuacultura Sustentables. H. Congreso de la Unión, México. Diario Oficial de la Federación. 2018. Desde:

http://www.diputados.gob.mx/LeyesBiblio/pdf/LGPAS_240418.pdf

Ley General de Vida Silvestre. H. Congreso de la Unión, México. Diario Oficial de la Federación. 2018. Desde: http://www.diputados.gob.mx/LeyesBiblio/pdf/146_190118.pdf

Ley General del Equilibrio Ecológico y Protección al Ambiente. H. Congreso de la Unión, México. Diario Oficial de la Federación. 2017. Desde http://www.diputados.gob.mx/LeyesBiblio/ref/lgeepa.htm

Ley General para la Prevención y Gestión Integral de Residuos. H. Congreso de la Unión, México. Diario Oficial de la Federación. 2018. Desde:

http://www.diputados.gob.mx/LeyesBiblio/pdf/263_190118.pdf 
Quaestio Iuris

Trabalho recebido em 31 de março de 2020

Aceito em 01 de junho de 2020 